\title{
Combined Electrocoagulation, Electrolysis and Photocatalysis Technologies Applied to Ship Sewage Treatment
}

\author{
Yu Qing, Yu Hang, Liu Xuelei, Wang Hui, and Xu Shu
}

\begin{abstract}
To develop new ship sewage treatment method, an electrochemical treatment device combined technologies of electrocoagulation, electrolyzing and photocatalysis was utilized to treat the stimulated ship sewage. The experimental showed that through the treatment of the combined technologies, BOD5, COD, TSS and Thermotolerant Coliform was reduced significantly and based on the reasonable structure design and operational parameters, UV irradiation method can be an alternative and potential technology of the traditional de-Chlorine methods. All the experimental results met the requirements of IMO resolution MEPC.159(55). This new electrochemical method and device will be very competitive for sewage treatment in the future.
\end{abstract}

Index Terms-Sewage, electrocoagulation, electrolyzing, photocatalytic reaction.

\section{INTRODUCTION}

With the rapid development of shipping industry and of marine resources exploration, marine environmental pollution is becoming more and more serious, and people are paying more and more attention to the marine environment protection. Compared with the city sewage, sewage from ships has its own characteristics: ship sewage has higher pollution load. due to the less flush water, COD, BOD and TSS have higher values and Less organic matter in sewage is decomposed because of the shorter discharge period [1]; the generation and discharge of is more unstable and Ship domestic sewage generated and discharged more unstable, characteristic significantly and the fluctuation of hydraulic load is obvious; the space condition and ship motion limit the application of the various conventional land sewage treatment process [2].

In order to control the discharge of ships and platforms more strictly, International Maritime Organization (IMO) had made and adopted resolution MEPC.159(55) on October 2006 -- Revised Guidelines on Implementation of Effluent Standards and Performance Tests for Sewage Treatment Plants and the resolution has been implemented on or after 1 January 2010. Resolution MEPC.159(55) made the requirements on the water quality of the discharged ship sewage, Table I shows the details:

The biochemical, physicochemical, electrochemical and the combined technologies are the main treatment technologies and systems for sewage treatment in the market.

Manuscript received April 15, 2015; revised June 18, 2015.

The authors are with Sunrui Marine Environment Engineering Co., Ltd., China (e-mail: yuq@sunrui.net, yuhang@sunrui.neti, liuxl@sunrui.net, wanghui@sunrui.net,xus@sunrui.net).
The biochemical technology adopts the microbial degradation of organic matter to lower the $\mathrm{BOD}_{5}$ and COD value of the sewage. Cyclic Activated Sludge Technology (CAST) and Membrane Bioreactor (MBR) are the main technologies of the biochemical treatment methods. Sewage is treated by physicochemical technology using coagulation, precipitation, filtration effect to remove the solid and disinfected by UV [3]. However most manufacturers adopt biochemical technology, electrochemical technology has gradually become the most potential technical in ship sewage treatment filed. The electrochemical method can oxide and disinfect the sewage through the electrode direct oxidation and the oxidants produced by electrolyzing the water. The electrochemical treatment system has obvious advantages: high degree of automation, same footprint, no biological culture, high hydraulic loading resistance and stable treatment effect, etc. due to the requirements to the performance and the materials of the electrode is very high, there are only few manufacturers have the commercial electrochemical treatment systems.

\begin{tabular}{cc}
\multicolumn{2}{c}{ TABLE I: REQUIREMENTS ON THE WATER QUALITY OF THE DISCHARGED } \\
SHIP SEWAGE \\
\hline Items & IMO Resolution MEPC. 159 (55) \\
\hline BOD $_{5}$ & $\leqq 125 \mathrm{mg} / \mathrm{L}$ \\
COD & $\leqq 35 \mathrm{mg} / \mathrm{L}$ \\
TSS & \\
Thermotolerant & $6-8.5$ \\
Coliform & \\
pH & $<00$ Thermotolerant Coliform $/ 100 \mathrm{ml}$ \\
Residual Chlorine & \\
(When chlorine is used & \\
as a disinfectant) &
\end{tabular}

In the present work, stimulated ship sewage treatment experiments using a new type of electrochemical sewage treatment system have been investigated.

\section{EXPERIMENTAL}

\section{A. Experimental Apparatus and Materials}

Sunrui electrolyzing sewage treatment system. The system is composed of electrocoagulation unit, electrolysis unit and de-chlorine unit, Collection Tanks, Macerator Pump, Seawater Pump and Blower fan, etc. The details of the system are shown in Fig. 1. 


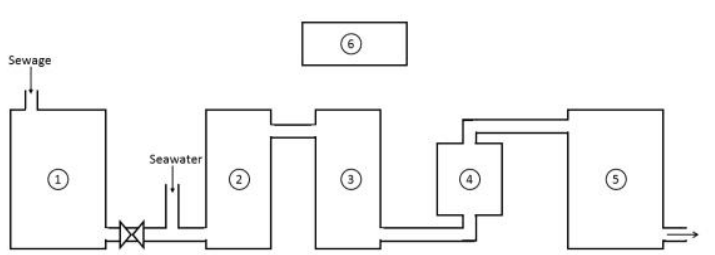

(1) Collection tank 1; (2) Electrocoagulation unit; (3) Collection tank 2; (4) Electrolysis uni; (5) De-chlorine unit, (6) Control cabinet

Fig. 1. Sunrui electrolyzing sewage treatment system.

The tank body of tanks, electrocoagulation unit, electrolysis unit and de-chlorine unit is made of Q235B and the external side is coated by anti-corrosion coating and the internal side is coated by coal tar epoxy.

The electrode of the electrocoagulation unit is aluminium with the purity $>99 \%$. The anode of the electrolysis unit is made of titanium and coated with a special DSA coating (Dimensionally Stable Anode) and the cathode is made of titanium. The Light-source UV lamps are used in de-chlorine unit. All the other metal components which contacting the water are made of $316 \mathrm{~L}$ stainless steel.

\section{B. Experimental Sewage}

The test water is the stimulated ship sewage which is composed of fresh sewage from office area sewer and kitchen wash water (The volume ratio is $4: 1$ ). In order to increase the pollution degree of sewage, glucose, Starch and silt had been added into the sewage. The parameters of the stimulated sewage are shown in Table II.

TABLE II: THE PARAMETERS OF THE STIMULATED SEWAGE

\begin{tabular}{ccccccc}
\hline Item & $\begin{array}{c}\mathrm{BOD}_{5} \\
\mathrm{mg} / \mathrm{l}\end{array}$ & $\begin{array}{c}\mathrm{COD} \\
\mathrm{mg} / \mathrm{l}\end{array}$ & $\begin{array}{c}\text { Thermotolerant Coliform } \\
/ 100 \mathrm{ml}\end{array}$ & $\mathrm{pH}$ & $\begin{array}{c}\mathrm{TSS} \\
\mathrm{mg} / \mathrm{l}\end{array}$ & Residual Chlorine mg/l \\
\hline \multirow{2}{*}{ Value } & $698-76$ & $1211-126$ & $1.7 \times 10^{4}-1.2 \times 10^{5}$ & $7.05-7.12$ & $\begin{array}{c}589-72 \\
9\end{array}$ & 0 \\
& 9 & 7 & & & 9 & \\
\hline
\end{tabular}

TABLE III: TREATMENT Results OF THE THREE TEST CyCleS

\begin{tabular}{|c|c|c|c|c|c|c|c|}
\hline Test cycle & Sampling point & $\begin{array}{c}\text { BOD5 } \\
\mathrm{mg} / \mathrm{l}\end{array}$ & $\begin{array}{l}\text { COD } \\
\mathrm{mg} / 1\end{array}$ & Thermotolerant Coliform $/ 100 \mathrm{ml}$ & $\mathrm{pH}$ & $\begin{array}{l}\text { TSS } \\
\mathrm{mg} / 1\end{array}$ & Residual Chlorine mg/l \\
\hline \multirow{4}{*}{ The first test cycle } & 1 & 698 & 1267 & $1.20 \times 10^{5}$ & 7.05 & 635 & 0 \\
\hline & 2 & 264 & 562 & $1.45 \times 10^{4}$ & 6.87 & 238 & 0 \\
\hline & 3 & 28 & 137 & 123 & 7.46 & 111 & 18.6 \\
\hline & 4 & 13 & 78 & 1 & 7.38 & 15 & 0.02 \\
\hline \multirow{4}{*}{ The second test cycle } & 1 & 769 & 1211 & $1.05 \times 10^{5}$ & 7.08 & 589 & 0 \\
\hline & 2 & 285 & 612 & $1.23 \times 10^{4}$ & 6.76 & 256 & 0 \\
\hline & 3 & 26 & 121 & 56 & 7.23 & 124 & 17.8 \\
\hline & 4 & 16 & 66 & 1 & 7.35 & 21 & 0.05 \\
\hline \multirow{4}{*}{ The third test cycle } & 1 & 734 & 1232 & $1.7 \times 10^{4}$ & 7.12 & 729 & 0 \\
\hline & 2 & 312 & 548 & $1.03 \times 10^{4}$ & 6.85 & 277 & 0 \\
\hline & 3 & 38 & 146 & 48 & 7.13 & 96 & 18.9 \\
\hline & 4 & 20 & 87 & 1 & 7.15 & 15 & 0.1 \\
\hline
\end{tabular}

\section{Experimental Method}

As a sewage storage tank, collection tanks have the liquid level switch for controlling liquid level. The seawater pump pumps the seawater to mix with the sewage before flow into the electrocoagulation unit. The main structure of electrocoagulation unit is a cabin with Aluminum plates. The sewage treated by the electrocoagulation unit flow out of the unit and flow into collection tank 2 . The sewage is pumped from tank 2 to electrolysis unit. In the electrolyzing chamber the sewage is oxidized and disinfected by electrolysis reactors and flow into the de-chlorine unit. The de-Chlorine unit adopts UV technology using UV irradiation to make the photocatalytic reactions occur and decompose the residual Sodium Hypochlorite. Finally, the Drain pump drains the treated sewage out of the system.

Three test cycles have been conducted and four sampling points was set in each cycle: 1 ) collection tank 1 ; 2) outlet of the electrocoagulation unit; 3) outlet of the electrolysis unit and 4) outlet of the de-Chlorine unit.

\section{Analysis Methods}

1) Total Suspended Solids (TSS)

Revised Guidelines on Implementation of Effluent Standards and Performance Tests for Sewage Treatment Plants (MEPC. 159(55))

2) 5-day Biochemical Oxygen Demand $\left(\mathrm{BOD}_{5}\right)$

ISO 5815-1-2003: Water quality-Determination of biochemical oxygen demand after $\mathrm{n}$ days (BODn) - Part 1: Dilution and seeding method with allylthiourea addition

Chemical Oxygen Demand (COD)

ISO 15705-2002 Water quality-Determination of the chemical oxygen demand index (ST-COD) - Small-scale sealed-tube method

3) Thermotolerant Coliform

ISO 9308-2-1990 Water quality-Detection and 
enumeration of coliform organisms, thermotolerant coliform organisms and presumptive Escherichia coli - Part 2: Multiple tube (most probable number) method $\mathrm{pH}$.

GB/T 6920-1986 Water quality-Determination of $\mathrm{pH}$ value-Glass electrode method

Residual Chlorine

CB 3328.6-1988 Water quality-Determination of free chlorine and total chlorine.

\section{RESULTS AND DISCUSSION}

Table III presents the treatment results of the three test cycles.

Changes of $\mathrm{BOD}_{5}, \mathrm{COD}$, Thermotolerant Coliform, $\mathrm{pH}$, TSS and Residual Chlorine of the four sampling points in the three test cycles are shown in Fig. 2 to Fig. 7 respectively.

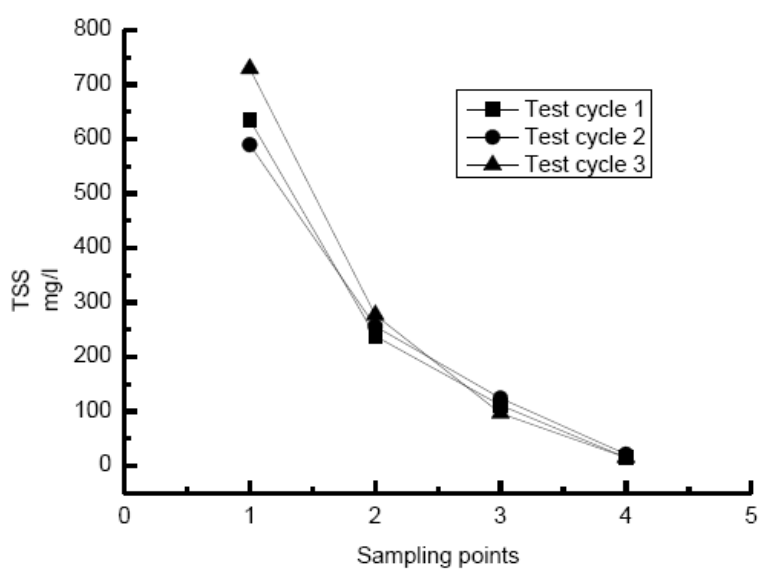

Fig. 2. BOD5 changes of the four sampling points in the three test cycles.

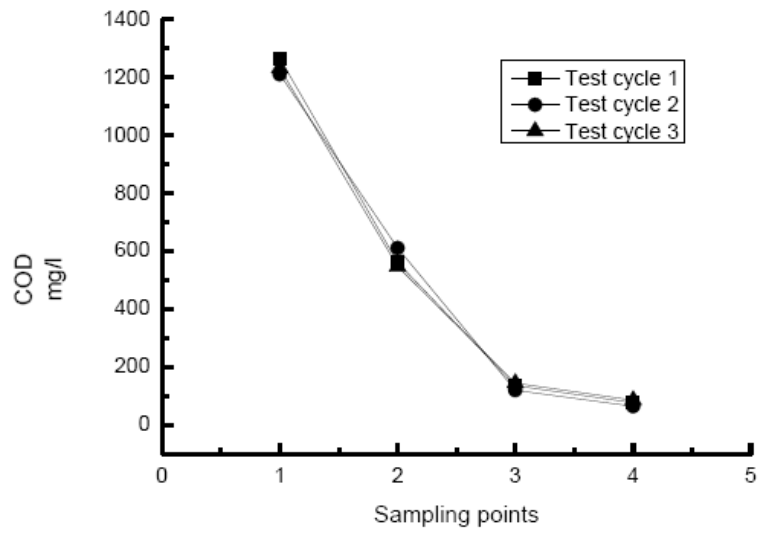

Fig. 3. COD changes of the four sampling points in the three test cycles.

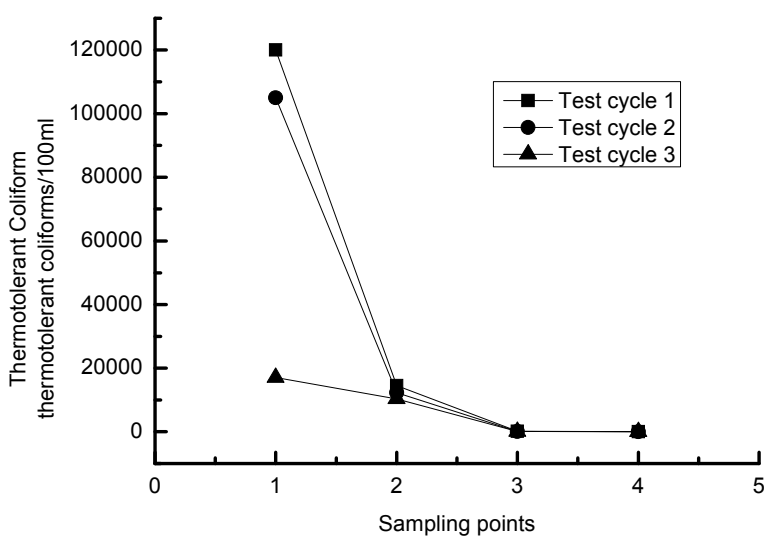

Fig. 4. Thermotolerant coliform changes of the four sampling points in the three test cycles.

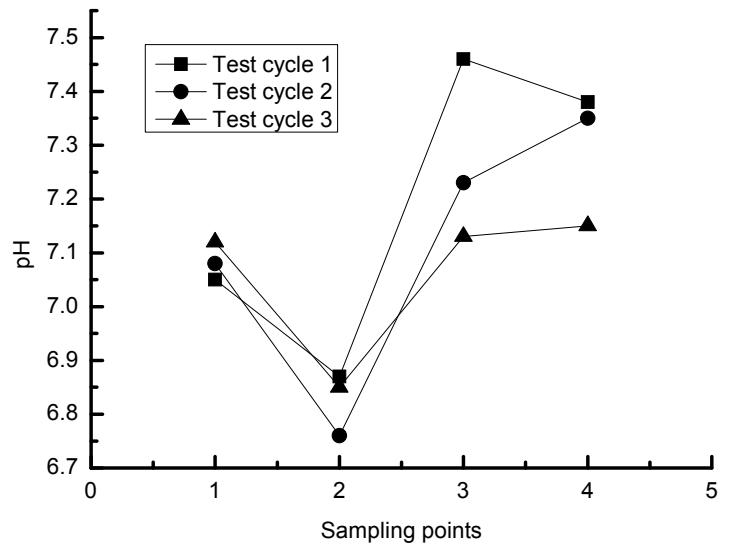

Fig. 5. pH changes of the four sampling points in the three test cycles.

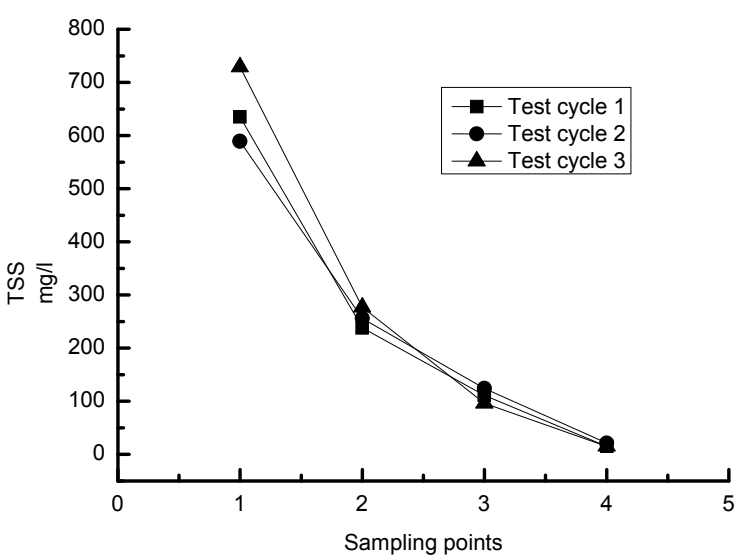

Fig. 6. TSS changes of the four sampling points in the three test cycles.

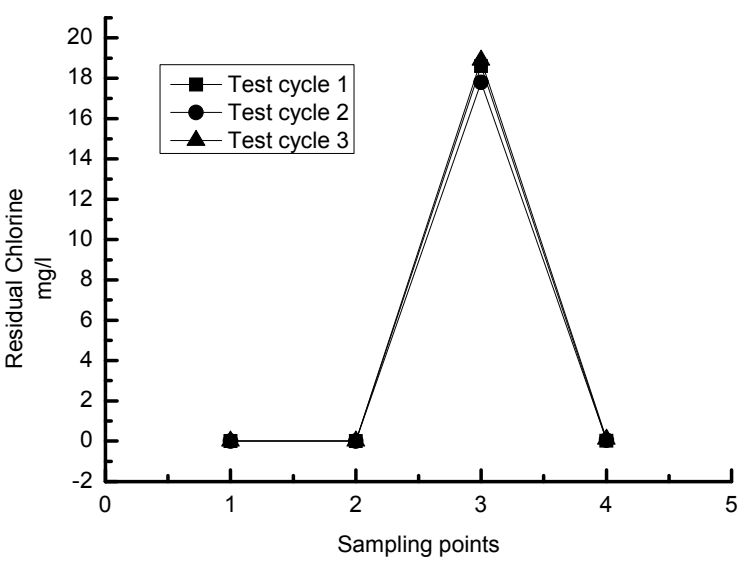

Fig. 7. Residual chlorine changes of the four sampling points in the three test cycles.

Fig. 2 and Fig. 3 show that the $\mathrm{BOD}_{5}$ and COD decrease with the processing of the treatment. In the electrocoagulation unit, the main structure of electrocoagulation unit is a cabin with Aluminum plates. Under the effect of the current, Aluminum plates dissolved and change into aluminum ion, the aluminum ion hydrolyzes and generates flocculants, which can act on impurities and form precipitates(equation (1) - (6)) [4]-[9]. The suspended solids, insoluble organic matter and part of the oil can be absorbed by the flocculants and precipitated to the bottom of the electrocoagulation unit. Meanwhile, electrolysis will generates tiny $\mathrm{H}_{2}$ and $\mathrm{O}_{2}$ bubbles. On the way up, the bubbles can absorb light suspended particles and water-repellent substance. Those impurities will float on water surface and can be cleaned automatically or 
manually. So the BOD5 and COD value decreased obviously.

$$
\begin{gathered}
\text { Anode } \mathrm{Al} \rightarrow \mathrm{Al}^{3+}+3 \mathrm{e} \\
\text { Cathode } 2 \mathrm{H}_{2} \mathrm{O}+2 \mathrm{e} \rightarrow \mathrm{H}_{2}+2 \mathrm{OH}^{-} \\
2 \mathrm{H}_{2} \mathrm{O} \rightarrow \mathrm{O} 2+4 \mathrm{H}^{+}+4 \mathrm{e} \\
\mathrm{Al}^{3+}+\mathrm{H}_{2} \mathrm{O} \rightarrow \mathrm{Al}(\mathrm{OH})^{2+}+\mathrm{H}^{+} \\
\mathrm{Al}(\mathrm{OH})^{2+}+\mathrm{H}_{2} \mathrm{O} \rightarrow \mathrm{Al}(\mathrm{OH})_{2}^{+}+\mathrm{H}^{+} \\
\mathrm{Al}(\mathrm{OH})_{2}^{+}+\mathrm{H}_{2} \mathrm{O} \rightarrow \mathrm{Al}(\mathrm{OH})_{3}+\mathrm{H}^{+}
\end{gathered}
$$

$\mathrm{BOD}_{5}$ and COD are further reduced on the outlet of the electrolysis unit. The anodes of the electrolysis unit are made of titanium and coated with a special DSA (Dimensionally Stable Anode) coating and the cathodes are made of titanium. The sewage flows through the space between the anodes and cathodes, under the anodes oxidation effect the organic matter is directly oxidized to $\mathrm{CO}_{2}$ and $\mathrm{H}_{2} \mathrm{O}$. Meanwhile, Sodium Hypochlorite which is a strong oxidant is produced by the electrochemical reactions (7) [10], (8) and (9). Sodium Hypochlorite can also oxidize the organic matters to lower the COD and $\mathrm{BOD}_{5}$.

$$
\begin{gathered}
\text { Anode: } 2 \mathrm{Cl}^{-} \rightarrow \mathrm{Cl}_{2}+2 \mathrm{e} \\
\text { Cathode: } 2 \mathrm{H}_{2} \mathrm{O}+2 \mathrm{e} \rightarrow 2 \mathrm{OH}-+\mathrm{H}_{2} \\
\text { Overall reaction: } \mathrm{NaCl}+\mathrm{H}_{2} \mathrm{O} \rightarrow \mathrm{NaClO}+\mathrm{H}_{2}
\end{gathered}
$$

The sewage containing certain concentration Sodium hypochlorite flows into the de-Chlorine unit. Several UV lamps quartz tubes are set in the unit and irradiate the sewage before the sewage flow out of the unit. Experimental shows that $\mathrm{COD}$ and $\mathrm{BOD}_{5}$ continue to be reduced in this treatment step. Two reasons may be responsible for this change: one reason is the Sodium hypochlorite continue to oxidize organic matter in de-Chlorine unit before Sodium hypochlorite was total degraded, another is under the UV lamps irradiation, photocatalytic reactions occur and decompose the residual Sodium Hypochlorite. Meanwhile an active Oxygen with high oxidation ability is produced which can also oxidize the organic matters in the water [11]. The reactions are listed below:

$$
\mathrm{NaClO} \stackrel{\mathrm{uv}}{\longrightarrow} \mathrm{NaCl}+[\mathrm{O}]
$$

$$
[\mathrm{O}]+\text { Organic Matters } \longrightarrow \mathrm{CO}_{2}+\mathrm{H}_{2} \mathrm{O}
$$

According to S. Raghu [10], OH can also be generated during the reactions and oxidize the organic compounds to $\mathrm{CO}_{2}$ and $\mathrm{H}_{2} \mathrm{O}$.

Fig. 4 shows the Thermotolerant Coliform change in the whole treatment process. In the electrocoagulation unit, the produced flocculants carry some particles out of the sewage, so part of the Thermotolerant Coliform which is contained in the particles is also separated from the sewage. In electrolysis unit and de-Chlorine unit, under the combined effects of Sodium Hypochlorite oxidation, UV irradiation and active Oxygen Oxidation, the Thermotolerant Coliform is almost killed [12].

Fig. 5 shows that the $\mathrm{pH}$ increases obviously after the electrolysis unit, because during the electrolysis reaction, the $\mathrm{OH}-\mathrm{can}$ be produced according to reaction (8).

Fig. 6 shows the change of TSS. Due to the electrocoagulation effect of the electrocoagulation unit and the settlement effects of collection tank 2 and de-Chlorine unit, The TSS is separated and decrease gradually.

Fig. 7 shows the change of residual Chlorine. According to reaction (9), certain concentration Sodium Hypochlorite is produced in electrolysis unit. Due to its decay and especially the UV irradiation, Sodium Hypochlorite is decomposed to the allowable discharge concentration. The traditional methods to neutralize sodium hypochlorite are to add the neutralizer (sodium thiosulfate, sodium sulfite and sodium purosulfate, etc.) to the water. UV irradiation technology avoids to transport, storage and prepare the chemicals and can't bring the second pollution.

\section{CONCLUSIONS}

1) Based on the combined technologies of electrocoagulation, electrolyzing and photocatalytic reaction and appropriate operational parameters, the electrochemical sewage treatment system can meet the requirements of IMO resolution MEPC.159(55);

2) The anode of the electrolysis unit which is made of titanium and coated with a special DSA (Dimensionally Stable Anode) coating can be used for the advanced treatment of organic compounds in the water;

3) Based on the reasonable structure design and operational parameters, UV irradiation method can be an alternative and potential technology of the traditional de-Chlorine methods.

\section{REFERENCES}

[1] L. F. Dong, H. Xu, and W. X. Guang, "Study on the characteristics and treatment plant of domestic sewage aboard ships," Journal of Xi'an University of Architecture \& Technology, vol. 37, no. 4, pp. 536-539. 2005.

[2] J. Ouyang and Q. Liu, Marine Auxiliary Machinery, China Communications Press, Beiing, 1981.

[3] S. Fraval, "Treatment of grey and black water with orelis MBR: The plate and frame technology," Ballast Water and Waste Water Treatment Aboard Ships and in Ports, Bremen: Eule \& Partners International Consulting, 2004

[4] G. Mouedhen, M. Feki, M. P. Wery, and H. F. Ayedi, "Behavior of aluminum electrodes in electrocoagulation process," Journal of Hazardous Materials, vol. 150, pp. 124-135, 2008.

[5] G. Chen, X. Chen, and P. L. Yue, "Electrocoagulation and electroflotation of restaurant wastewater," J. Environ. Eng., vol. 126, pp. 858-863, 2000.

[6] X. Chen, G. Chen, and P. L. Yue, "Separation of pollutants from restaurant wastewater by electrocoagulation," Sep. Purif. Technol., vol. 19, pp. 65-76, 2000.

[7] N. Adhoum, L. Monser, N. Bellakhal, and J. E. Belgaied, "Treatment of electroplating wastewater containing $\mathrm{Cu}^{2+}, \mathrm{Zn}^{2+}$ and $\mathrm{Cr}(\mathrm{VI})$ by electrocoagulation," J. Hazard. Mater., vol. B 112, pp. 207-213, 2004.

[8] M. Y. A. Mollah, P. Morkovsky, J. A. G. Gomes, M. Kesmez, J. Parga, and D. L. Cocke, "Fundamentals, present and future perspectives of electrocoagulation," J. Hazard. Mater., vol. B 114, pp. 199-210, 2004.

[9] M. Kobya, H. Hiz, E. Senturk, C. Aydiner, and E. Demirbas, "Treatment of potatochips manufacturing wastewater by electrocoagulation," Desalination, vol. 190, pp. 201-211, 2006.

[10] S. Raghu, C. W. Lee, S. Chellammal, S. Palanichamy, and C. Ahmed Basha, "Evaluation of electrochemical oxidation techniques for 
degradation of dye effluents - A comparative approach," Journal of Hazardous Materials, vol. 171, pp. 748-754, 2009.

[11] P. He, S. X. Li, and L. Yu, "Treatment of wastewater in N -phosphonomethyl iminodiacetie, acid production by ultraviolet light $-\mathrm{NaClO}$ oxidation process," Environmental Protection of Chemical Industry, vol. 31, no. 5, pp. 447-449, 2011.

[12] M. T. Guo and H. Y. Hu, "Influence of different combination modes of uv and chlorine on inactivation effect of Escherichia coli, China," Water and Wastewater, vol. 23, no. 17, pp. 80-83, 2007.

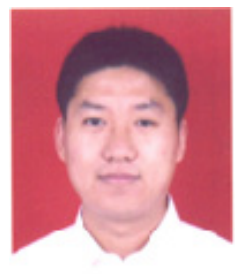

Yu Qing was born in Luoyang in 1980. He received the $\mathrm{PhD}$ from Institute of Oceanology, Chinese Academy of Sciences in 2008 in Qingdao, PR China. His major is marine chemistry. From 2008 to present he works in Sunrui Marine Environment Engineering CO., Ltd and focuses on developing new water treatment and anti-corrosion technology and products. His current research interests are ballast water and sewage treatment technologies.

Dr. Yu had been honored with "the First Prize of Science and Technology of Chinese Society of Naval Architects and Marine Engineers: Ballast Water Treatment System Using Electrolyzing Technology". 